\title{
Participação política das mulheres zapatistas: desafios e resistências
}

\author{
Francine Rebelo (UFSC) ${ }^{1}$ \\ Luiz Antonio Guerra (USP) ${ }^{2}$
}

\begin{abstract}
Resumo
Este artigo aborda a participação política feminina dentro do movimento zapatista mexicano, a partir da análise do livro "Participação das mulheres no governo autônomo", que consiste em uma cartilha produzida pelas próprias mulheres em ocasião do evento "Escuelita Zapatista", ocorrido no estado de Chiapas, no ano de 2013. Esta cartilha reúne valiosos depoimentos das zapatistas sobre sua realidade, em especial no que diz respeito à sua participação política nas diversas instâncias do governo autônomo. No presente artigo tratamos, portanto, de temas relacionados à Lei Revolucionária de Mulheres, às mudanças ocorridas a partir do levante de 1994, suas conquistas e os problemas ainda enfrentados pelas mulheres indígenas nas suas comunidades rebeldes.
\end{abstract}

Palavras-chave: gênero, zapatismo, participação política.

\section{Resumen}

Este artículo discute la participación política femenina en el movimiento zapatista mexicano, desde el análisis del libro "Participación de las mujeres en el gobierno autónomo", que consiste en un cuaderno producido por las propias mujeres en el marco del evento "Escuelita Zapatista", celebrado en el estado de Chiapas, en 2013. Este cuaderno recoge valiosos testimonios de las zapatistas sobre su realidad, sobre todo con respecto a su participación política en los diferentes niveles del gobierno autónomo. En este artículo planteamos, por lo tanto, temas relacionados con la Ley Revolucionaria de Mujeres, los cambios ocurridos a partir del levantamiento de 1994, sus logros y los problemas que aún enfrentan las mujeres indígenas en sus comunidades rebeldes.

Palavras-clave: género, zapatismo, participación política.

\section{Introdução}

Ao nos aproximarmos do movimento indígena zapatista no estado mexicano de Chiapas $^{3}$, uma das primeiras características que nos chama

\footnotetext{
${ }^{1}$ Mestre em Antropologia - Universidade Federal de Santa Catarina (UFSC). Contato: fprebelo@yahoo.com.

${ }^{2}$ Doutorando em Sociologia - Faculdade de Filosofia, Letras e Ciências Humanas (FFLCH) - Universidade de São Paulo (USP). Contato: guerra.luizantonio@gmail.com.

${ }^{3}$ O Estado de Chiapas abriga a segunda maior população indígena do México, equivalente a 1.330.981 pessoas, do total de 4,3 milhões de habitantes do estado, de acordo com dados de 2005 da Comisión Nacional para el Desarrollo de los Pueblos Indígenas (CDI). As comunidades indígenas de Chiapas são descendentes dos povos maias que há milênios têm habitado a região correspondente ao sul do México e alguns países centro-americanos, como Guatemala e Belize, apresentando atualmente uma grande variedade étnica. Segundo dados do Instituto Nacional de Estadística e Geografía (INEGI) de 2010, aproximadamente $24 \%$ da população fala uma língua indígena, 17,8\% não leem ou escrevem, na maioria dos casos nem sequer falam a língua oficial espanhola. A porcentagem de analfabetismo é ainda maior entre as mulheres: 21,82\%. Uma publicação de 2012 do Centro de Derechos Humanos Fray Bartolomé de las Casas (Frayba) aponta que Chiapas ocupa o segundo lugar nacional em desnutrição e o terceiro em mortalidade materna. O estado ocupa a última posição entre todas as entidades federativas mexicanas na lista de Índice de Desenvolvimento Humano (IDH) (PNUD, 2010) e, dentro do estado, a região com
} 
atenção é a posição política central ocupada pelas mulheres. Este artigo retoma dados empíricos resultantes da participação na primeira edição da "Escuelita Zapatista", na Cátedra Tata Juan Chávez Alonso e nas festividades de comemoração da primeira década de existência das zonas autônomas "Caracol I - La Realidad" e "Caracol III - La Garrucha". Assim, este artigo se apoia na vivência em Chiapas entre os meses de maio e setembro de 2013. Também se reflete a partir do discurso das mulheres zapatistas apresentado na cartilha ${ }^{4}$ intitulada "Participação das Mulheres no Governo Autônomo" (EZLN, 2013c), de autoria das próprias comunidades autônomas.

Anterior ao levante de primeiro de janeiro de 1994, destacaram-se a atuação de lideranças femininas dentro do Exército Zapatista de Liberação Nacional (EZLN), como a da Comandanta Ramona, quem encabeçou um grupo de mulheres zapatistas que mobilizou as comunidades em torno da problemática da exploração feminina e realizaram uma ampla consulta, dando origem à Lei Revolucionária de Mulheres, em vigor desde então nos territórios rebeldes.

A Comandanta Ramona também foi uma das principais lideranças na coordenação estratégica do levante armado de 1994, quando o EZLN tomou de assalto cinco sedes municipais do estado de Chiapas. Além disso, participou ativamente das mesas de negociação com o governo mexicano nos Diálogos de San Andrés ${ }^{5}$ e liderou a caravana zapatista que alcançou a Cidade do México em 1996.

Já em março de 2001, quando novamente o comando do EZLN alcançou a praça central da capital do país e conseguiu ter direito à palavra na tribuna do congresso nacional mexicano, coube à outra mulher, a Comandanta Esther, falar em nome de todas as comunidades zapatistas, proferindo em seu discurso as seguintes palavras: "Aquí estoy yo, una mujer indígena".

Aquelas que se destacaram no movimento zapatista representam a realidade, desafios, conquistas e luta cotidiana de milhares de mulheres indígenas nas comunidades rebeldes de Chiapas. A forte participação política feminina está presente não apenas nos altos cargos da estrutura do EZLN, mas em todas as instâncias comunitárias da organização política

maior grau de marginação é justamente onde há maior incidência de população indígena (e de influência do EZLN).

\footnotetext{
${ }^{4}$ Materiais impressos em formato de revista ou cartilha, coloridos e com fotos, se encontram disponíveis em diversos sites na internet.

${ }^{5}$ Reuniões entre o EZLN e o governo mexicano na cidade de San Andrés de Larráinzar, que resultou em acordos sobre direitos e cultura indígenas firmados em 1996, não cumpridos pelo governo até os dias de hoje.
} 
autônoma. Nos trabalhos diários se fortalecem as bases de apoio e sua resistência para fazerem valer a Lei Revolucionária de Mulheres.

Nos depoimentos recebidos, podemos perceber que o avanço do movimento e grande parte das conquistas femininas ocorridas nas comunidades ao longo das últimas três décadas, é auto atribuído. Para elas, independentemente de religião ou partido político, foi a organização autônoma que as fez despertar e reconhecer-se enquanto sujeitos políticos, capazes de exercer todo tipo de trabalho e assumir qualquer cargo dentro da organização comunitária. O desenvolvimento das comunidades rebeldes e das suas instituições autônomas fez com que as zapatistas se apoiassem e se organizassem em torno de problemas comuns e de demandas de participação.

A partir da mobilização da sociedade civil nacional e internacional nos dias que sucederam seu levante em 1994, o EZLN recuou suas ocupações militares nas cidades tomadas. Esse retorno dos rebeldes para suas comunidades, inaugurou um movimento civil com estratégias pacíficas, criativas e inovadoras que permitiram o diálogo com o governo e com a sociedade. Ditas estratégias marcaram um profundo câmbio passando-se da perspectiva militar para a civil, na qual as comunidades assumiram a centralidade política na construção da sua autonomia. Nos últimos vinte anos, os/as zapatistas iniciaram um profundo processo de reorganização comunitária e criação de instituições autônomas voltadas para a sociedade civil.

Em 2003, o EZLN anunciou a criação dos cinco "Caracóis" e das "Juntas de Bom Governo", instâncias máximas da organização e de encontro com a sociedade civil, avançando no processo de construção da autonomia zapatista. Em discurso pronunciado na ocasião das celebrações do nascimento dos "Caracóis", a Comandanta Esther anunciou que, sem pedir nenhuma permissão ao governo, as comunidades indígenas rebeldes estavam executando o que foi acordado nos Diálogos de San Andrés (Discurso da Comandanta Esther, 09/08/2003) ${ }^{6}$.

Desde então o governo autônomo zapatista organiza-se em três níveis: primeiro as comunidades e autoridades locais; segundo os Municípios Autônomos Rebeldes Zapatistas (MAREZ) e, terceiro, as "Juntas de Bom Governo", responsáveis pela coordenação de um total cinco zonas ou cinco "Caracóis" - La Realidad, Oventik, La Garrucha, Morelia e Roberto Barrios. As

\footnotetext{
6 Todos os comunicados oficiais do EZLN podem ser encontrados na rede mundial de computadores, nos sites: www.enlacezapatista.ezln.org.mx e www.palabra.ezln.org.mx e na cartilha "Participação das Mulheres no Governo Autônomo", de autoria das comunidades por ocasião da "Escuelita Zapatista".
} 
"Juntas de Bom Governo" tem atribuição de coordenação dos municípios autônomos e compõem-se paritariamente por mulheres e homens. Os 12 a 28 integrantes trabalham coletivamente a tomada de decisões e são substituídos a cada três anos.

No segundo semestre de 2013 , o movimento zapatista comemorava três datas emblemáticas da sua história de luta: trinta anos da fundação clandestina; vinte anos da insurreição que apresentou o movimento em $1^{\circ}$ de janeiro de 1994; e dez anos da criação dos "Caracóis" e "Juntas de Bom Governo". Ditas comemorações constituem resultados do processo de organização das comunidades e de instituições autônomas.

No marco dessas datas, entre os dias 08 e 19 de agosto de 2013 , as/os zapatistas mobilizaram ativistas e movimentos sociais de todo o mundo. Os cinco "Caracóis" comemoraram seus dez anos de existência e resistência, retomaram o Congresso Nacional Indígena (CNI) e a Cátedra Tata Juan Chávez Alonso, realizados no Centro Integral de Desarrollo Comunitario Indígena (Cideci), em San Cristóbal de Las Casas, Chiapas. Também Convidaram cerca de 1.500 pessoas, de todas as idades e continentes, para participar da primeira edição da "Escuelita Zapatista", ocorrida na semana do dia 11 a 17 de agosto de $2013^{7}$.

A proposta da "Escuelita Zapatista" foi proporcionar uma semana de vivencias para que os ativistas se colocassem na posição de "estudantes", para "aprender" sobre a realidade, pensamento e valores zapatistas através da experiência cotidiana nas próprias comunidades rebeldes, vivendo e trabalhando com as bases de apoio que, na sua perspectiva, representam e estruturam de fato não apenas a história, mas todo o pensamento do movimento.

De acordo com os Subcomandantes Marcos e Moisés, em uma série de comunicados prévios ao evento, a "Escuelita" não era o momento para a realização de entrevistas ou propostas para implantação de projetos, mas tempo para escutar o que as comunidades indígenas têm a dizer, concentrando-se assim nos discursos e formas de conhecimento que foram sistematicamente suprimidos em mais de quinhentos anos de colonialidade.

Foram vários meses dedicados a elaborar o material de apoio e treinamento para receber as/os "estudantes". Na vivencia cada "estudante" contou com um guardião ou guardiã (chamados nas línguas maias de votán),

\footnotetext{
${ }^{7}$ Essa experiência é abordada na dissertação intitulada "Democracia, Justiça, Liberdade: Lições da Escuelita Zapatista", defendida em abril de 2014 no Programa de Pós-Graduação em Sociologia da Universidade de Brasília (UnB).
} 
responsáveis por seu "aprendizado" e estadia na comunidade. As/os convidadas/os também contaram com o cuidado de uma família indígena zapatista, com a qual comiam, trabalhavam, descansavam, etc. Essa vivência no cotidiano familiar foi essencial como estratégia de "ensino" da "Escuelita", pois, "segundo os zapatistas, o lugar de ensino-aprendizagem é o coletivo, ou seja, a comunidade" (Comunicado do EZLN de 30/07/2013).

A "Escuelita Zapatista" mostrou aos indivíduos e movimentos organizados como vivem as e os indígenas rebeldes no dia-a-dia. Proporcionando um processo de autoanálise do movimento quanto aos acertos e erros nas últimas duas décadas nas tarefas cotidianas de organização comunitária. Neste evento, também buscaram compartilhar suas experiências de autonomia e como resistem ao racismo cultural e aos ataques de paramilitares e do estado mexicano. As/os convidadas/os receberam como "material didático" quatro cartilhas produzidas pelas próprias comunidades: Governo Autônomo I e II, Resistência Autônoma e Participação das Mulheres no Governo Autônomo.

Essas quatro cartilhas são materiais privilegiados para acessar as compreensões do movimento, pois estão constituídas por testemunhos dos membros das comunidades, contrastando com os comunicados habituais dos porta-vozes divulgados na internet. As cartilhas consistem em um esforço inédito de sintetizar o pensamento que emerge da prática cotidiana das comunidades. São uma tentativa pública de pensar, refletir e explicar o seu projeto político, sua realidade rebelde, as relações entre seus membros e o processo de construção das instituições autônomas zapatistas. Trata-se de um momento reflexivo do movimento, no qual é apresentada a maneira com que as comunidades estão enxergando suas próprias práticas.

As cartilhas foram entregues no ato de inscrição dos 1.500 estudantes convocados. Cada estudante informou-se à qual "Caracol" era destinado e se organizaram as caravanas, coordenadas pelo Subcomandante Moisés. Após a recepção das/dos convidadas/os no centro de cada "Caracol", houve um momento de discussão coletiva do conteúdo do material fornecido. Cada estudante conheceu sua guardiã ou guardião e foi encaminhado/a para a respectiva comunidade na qual uma família já o/a esperava. Ao fim de cada dia de trabalho eram separadas algumas horas para que o/a estudante lesse os livros em companhia da família e guardiães zapatistas, e tiravam-se as dúvidas.

A cartilha "Participação das Mulheres no Governo Autônomo" consiste em um esforço de juntar depoimentos de mulheres indígenas zapatistas em torno de temas caros à realidade feminina nas suas comunidades. A 
cartilha é organizada a partir das discussões e textos produzidos de acordo com a experiência das zapatistas. Se estrutura respeitando a divisão do território zapatista em cinco "Caracóis". Na parte que cabe ao "Caracol I La Realidad: Madre de los Caracoles, Mar de nuestros sueños", a zapatista Eloísa escreve a introdução, Nabil e Marisol relatam as dificuldades da participação das mulheres nos trabalhos.

No "Caracol II - Oventik: Resistencia y rebeldia por la humanidad", a zapatista Guadalupe escreve a introdução; Letícia sobre a participação das mulheres nas "Juntas de Bom Governo"; Silvia sobre a participação das companheiras nos municípios autônomos e em outros cargos; Verónica sobre a participação das mulheres nas diferentes áreas de trabalho; Yolanda e Guadalupe sobre o exercício da Lei Revolucionária de Mulheres; Claudia sobre a proposta de ampliação da Lei Revolucionária de Mulheres e todas produzem em conjunto um relato sobre as dificuldades da participação das mulheres nos trabalhos.

Na parte escrita pelas bases de apoio do "Caracol III - La Garrucha: Resistencia hacia un nuevo amanecer", a zapatista Andrea escreve a introdução; Ana Yolanda sobre a participação das mulheres na luta e autonomia; e Carolina, Susana, Manuela, Celina, Claudia, María Luisa, María, Andrea, Patricia e Ana Yolanda sobre os direitos das mulheres.

Já na parte referente ao "Caracol IV - Morelia: Torbellino de nuestras palabras", a zapatista Claudia escreve a introdução; Alejandra sobre a participação das companheiras no governo autônomo e como responsáveis de comissões; Amélia sobre o trabalho das companheiras na "Junta de Bom Governo" e sobre como se está exercendo a Lei Revolucionária de Mulheres; Andrea sobre a participação das companheiras nos Municípios Autônomos e as dificuldades que têm encontrado nas distintas instâncias no governo autônomo; e Verônica sobre a participação das mulheres como autoridades locais.

Por último, no "Caracol V - Roberto Barrios: Que habla para todos", a zapatista Ana escreve a introdução; Paulina, Ángeles, Rosalía, Karina, Dora e Alondra sobre a participação das companheiras nos distintos níveis de governo e áreas de trabalho; Valentina e Ana sobre a Lei Revolucionária de Mulheres; e Adamari e Ana sobre as dificuldades e obstáculos que as mulheres têm enfrentado nas distintas instâncias no governo autônomo.

\section{As zapatistas antes de 1994: colonialismo e mau governo}

Nos depoimentos compilados em "Participação das Mulheres no Governo Autônomo" podemos observar o objetivo das zapatistas em discutir em que 
pontos avançaram e quais ainda são os desafios das mulheres indígenas e integrantes da organização. Sendo assim, grande parte do material aborda as relações entre as e os próprios integrantes dos movimentos, destacando as dificuldades intra-comunitárias das mulheres zapatistas, assim como a especificidade das suas formas de resistências a partir da inserção na luta revolucionária. Nos textos das integrantes do movimento, nota-se um esforço de contextualização das ações das mulheres zapatistas, resgatando historicamente como era a participação e vivência das mulheres antes do levante revolucionário, bem como as consequências das imposições coloniais para a vida entre homens e mulheres indígenas.

A organização autônoma zapatista visa combater o "mau governo", termo que designa as instituições oficiais. Dessa forma, o termo se refere às formas hegemônicas de governo e de produção de conhecimento desde as primeiras investidas de Hernán Cortez até as reformas neoliberais do governo do PRI (Partido Revolucionário Institucional), que seguem em marcha com o atual presidente Henrique Peña Nieto. O "mau governo" representa tanto a colonização europeia e a imposição inicial das hierarquias dos valores ocidentais, quanto a reprodução da colonialidade em toda a história do México até os dias de hoje.

Em oposição ao "mau governo", o termo "bom governo" é usado para caracterizar as instituições autônomas zapatistas, marcando a diferença das suas próprias autoridades com os órgãos oficiais. Assim, de acordo com os relatos da "Escuelita", enquanto o "mau governo" promove a fome, destruição, esquecimento, ignorância, privilégios, prisões e morte, o "bom governo" organiza-se para promover os treze pontos de luta do zapatismo: trabalho, terra, alimentação, teto, saúde, educação, informação, cultura, independência, justiça, liberdade, democracia e paz.

O termo "mau governo" congrega uma série de críticas, que demonstram a consciência do movimento de que a realidade das suas comunidades é parte de um processo histórico global. As opiniões presentes nos discursos das mulheres zapatistas acerca da modernidade, globalização e capitalismo condenam suas características hierárquicas, racistas, coloniais e patriarcais - atingindo seu ápice no neoliberalismo.

Neste sentido, podemos notar que as integrantes dos cinco "Caracóis" associam diretamente a emergência do machismo nas comunidades indígenas com o advento da propriedade privada, agravada pela lógica neoliberal e pelo tratamento desrespeitoso dos "maus governos" em relação aos indígenas, principalmente às mulheres. 
Para Guadalupe, promotora de educação do "Caracol II - Oventik", região de Monterrey:

"Sabemos que desde el inicio las mujeres tenían un papel muy importante en la sociedad, en los pueblos, en las tribus. Las mujeres no vivian como vivimos ahora, eran respetadas, eran las más importantes para la conservación de la familia, eran respetadas porque dan la vida así como nosotros respetamos ahora a la madre tierra que nos da la vida. En ese tiempo la mujer tenía un papel importante pero a lo largo de la historia, con la llegada de la propiedad privada, eso se fue cambiando. La mujer al llegar la propiedad privada fue relegada, pasó a otro plano y llegó lo que llamamos el "patriarcado", con el despojo de sus derechos de las mujeres, con el despojo de la tierra, fue con la llegada de la propiedad privada que empezaron a mandar los hombres. Sabemos que con esta llegada de la propiedad privada se dieron tres grandes males, que son la explotación de todos, hombres y mujeres, pero más de las mujeres, como mujeres también somos explotadas por este sistema neoliberal. También sabemos que con esto llegó la opresión de los hombres hacia las mujeres por ser mujeres y también sufrimos como mujeres en este tiempo la discriminación por ser indígenas. Entonces tenemos estos tres grandes males, hay otros pero ahorita no estamos hablando de eso"(EZLN, 2013c, p. 18).

No trecho citado, nota-se o argumento de que o advento da propriedade privada e da divisão sexual dos trabalhos no interior das organizações indígenas deu origem à distinção de papéis onde as mulheres deixaram de ter um papel de importância, passando então a serem subjugadas pelos homens. Esta distinção que desvaloriza o trabalho das mulheres não se tratou de uma ação pontual, mas da inserção de uma lógica de pensamento que perdura ainda hoje e que dificulta a participação das mulheres indígenas nas organizações, gerando um sentimento de incapacidade apontado como um dos motivos centrais para falta de mobilização feminina.

Nessa perspectiva, a colonização provocou não apenas a repressão sistemática das crenças, ideias, imagens e símbolos, mas sobretudo a supressão, das formas de produção de conhecimento, representações, perspectivas e sistemas de significação. De acordo com o sociólogo decolonial Aníbal Quijano, o extermínio físico e cultural das antigas culturas fez com que elas fossem transfiguradas em subculturas 
camponesas analfabetas, garantindo sua identidade através da oralidade. Os povos originários que lograram sobreviver encontraram dificuldades para se expressar na modernidade fora dos padrões culturais dominantes (QUIJANO 1992). Com o passar dos séculos, mesmo após o reconhecimento pela Espanha do fim do colonialismo formal, no México em 1836, a Europa continua exercendo a dominação colonial.

Em dita independência formal, as formas de controle laboral e os nomes das categorias étnicas modificaram-se, mas a hierarquia se manteve (QUIJANO e WALLERSTEIN 1992). Desta forma, conforme o desenvolvimento histórico da modernidade trouxe o fim formal das regras coloniais e a abolição da escravidão, a etnicidade teve que ser reforçada por um consciente e sistemático racismo que, muitas vezes não explícito, esconde-se na hierarquia das práticas sociais - como o patriarcado.

Assim, Eloísa, ex integrante da "Junta de Bom Governo" do "Caracol I - La realidad", San Pedro Michoacán, aponta as implicações da incorporação feminina da superioridade masculina. Segundo ela, essa ignorância criada no capitalismo vem progressivamente sendo rompida através do apoio dos e das integrantes do movimento. Para Eloísa:

"En nuestra zona nosotras como compañeras no participábamos, nuestras compañeras de más antes no tenían esa idea de que nosotras como mujeres podemos participar, teníamos el pensamiento de que nosotras las mujeres sólo servimos para el hogar o cuidar los hijos, hacer la comida. Tal vez será por la misma ignorancia que hay en el capitalismo que eso era lo que teníamos en la cabeza, pero también nosotras como mujeres sentíamos el temor de no poder hacer cosas fuera del hogar y tampoco teníamos ese espacio de parte de los compañeros, no teníamos esa libertad de participar, de hablar, como que se pensaba que los hombres eran más que nosotras" (EZLN, 2013c, p. 6).

As discussões sobre as origens do patriarcado são diversas. De acordo com Rita Segato (2010), o pensamento feminista circula entre três posições: o feminismo eurocêntrico; uma segunda corrente que defende a inexistência de gênero no mundo pré-colonial; e uma terceira que reconhece uma organização patriarcal em sociedades indígenas, porém de menor intensidade.

De acordo com a autora, o feminismo eurocêntrico parte de uma noção universal de dominação patriarcal. Assim sendo, a mulher seria um sujeito a-histórico, subsumido em uma unidade representativa capaz de englobar 
todas as mulheres. Para Segato, trata-se de uma perspectiva que sustenta uma posição de superioridade das mulheres brancas, visto que sob a bandeira da universalidade pode-se transmitir os avanços da modernidade na temática de direitos, autorizando assim a intervenção a partir de uma missão civilizadora.

A segunda perspectiva teórica, afirma a inexistência das relações de gênero no mundo anterior a colonização. Apesar dos diferentes modos de experienciação das categorias de gênero, Segato afirma que a existência de evidências históricas que mostram de forma incontestável nomenclaturas de gênero, impossibilita a afirmação de que gênero seria uma infiltração colonial.

O que a autora propõe é a compreensão das relações de gênero a partir da implementação da ordem colonial moderna nas relações de gênero vivenciadas pelas aldeias. Assim, esta terceira posição teórica identifica nas sociedades indígenas uma organização patriarcal, ainda que de menor intensidade. Para Segato (2010: 117), neste grupo podemos mencionar:

"[...] as pensadoras feministas vinculadas ao processo de Chiapas, onde se constituiu uma situação paradigmática de resolução das tensões derivadas da dupla inserção das mulheres na luta pelos povos indígenas e na luta de frente interna por melhores condições de existência para o seu gênero".

A autora aponta que a colonização teve como consequência o agravamento interno das relações de poder dentro da comunidade, promovendo uma distância hierárquica que privilegia o poder masculino. Assim, apesar da afirmação de que sempre existiram relações desiguais de poder e prestígio, a intervenção colonial gerou um aumento muito significativo das desigualdades e consequentemente das opressões contra as mulheres.

A exposição da zapatista Ana, formadora de educação, é paradigmática neste sentido. Ela aponta para a existência de atividades diferenciadas a partir da introdução do modelo colonial, com a realização de trabalhos distintos por homens e mulheres:

"Hace muchos años atrás existía la igualdad entre hombres y mujeres porque no había uno que era más importante que el otro. Poco a poco empezó la desigualdad con la división del trabajo, cuando los hombres eran los que salían al campo a cultivar sus alimentos, salían de cacería para completar la alimentación de las familias y las mujeres se quedaban en la 
casa para dedicarse a los trabajos domésticos, así como también al hilado, el tejido de la ropa y a la elaboración de utensilios de cocina, como las ollas, vasos y platos de barro. [...] Así era la costumbre, el modo de vida que trajeron los españoles cuando vinieron a conquistar nuestros pueblos, eran los frailes quienes nos educaban e instruían en sus costumbres y conocimientos. Desde ahí nos enseñaron que la mujer tenía que servirle a los hombres y hacerle caso en todo momento cuando da órdenes, y que las mujeres deben cubrir su cabeza con un velo cuando van a la iglesia y que no tienen que fiar su mirada por cualquier lado, que tienen que tener agachadita su cabeza. Se consideraba que las mujeres eran los que hacian pecar a los hombres, por eso la iglesia no permitía que las mujeres fueran a la escuela, mucho menos que ocuparan cargos. Nosotros los pueblos indígenas lo agarramos como nuestra cultura la forma como los españoles trataban a sus mujeres, por esa razón en las comunidades empezó a surgir la desigualdad entre hombres y mujeres que sigue hasta ahora" (EZLN, 2013c, p. 62).

Para o EZLN (2013c) qualquer tipo de relação desigual de poder não é anterior a colonização. Porém, tampouco há menção de que gênero não fosse um princípio organizador das sociedades indígenas antes das relações coloniais. Assim, quando Ana afirma que "no había uno que era más importante que el outro", ela não deixa de fazer menção a um "outro" e atenta, principalmente, para os diferentes graus de importância atribuídos aos homens e às mulheres. Assim, a questão principal é analisar como progressivamente, as desigualdades criaram corpo nas comunidades indígenas e quais os desafios mulheres e homens devem ultrapassar internamente para participação coletiva e igualitária na luta revolucionária.

Neste sentido, o levante zapatista aparece como forma central de articulação, mostrando-se um marco na luta pela igualdade entre homens e mulheres, o que leva a zapatista Andrea a afirmar que:

"Antes de 94 habian sufrido mucho las compañeras, había humillaciones, maltratos, violaciones, pero al gobierno no le importaba eso, su trabajo es no más destruirnos como mujeres, no le importaba si es que hay una mujer que se enfermaba $o$ pides ayuda o auxilio, eso no le importa, pero nosotras como mujeres ahora ya no podemos dejarnos, tenemos que seguir adelante. En esos tiempos hubo sufrimiento, habia muchas 
humillaciones por lo que hacía el mal gobierno y también los finqueros, a las mujeres no las tomaban en cuenta". (Andrea, coordenadora de saúde, "Caracol III - La Garrucha", in: EZLN, 2013c, p. 38).

Claudia, coordenadora de três áreas de trabalho, San Manuel, e integrante do "Caracol III", afirma que a atuação destrutiva dos "maus governos" em relação às mulheres dava-se também através do descaso público em diversas esferas:

"Nosotras como mujeres tenemos el derecho a la educación, si no sabemos leer podemos seguir estudiando si queremos, por eso están nuestros promotores autónomos, para que nos enseñen, para que sigamos adelante. Como mujeres antes no éramos así, con los malos gobiernos no pudimos estudiar porque no teníamos dinero, por eso hasta ahora no sabemos hablar en castilla, ni leer, ni escribir, pero vamos a luchar hasta donde podamos con nuestra autonomía"(EZLN, 2013c, p. 41).

A tomada de consciência e organização coletiva das mulheres zapatistas conformam respostas e resistências não apenas aos modelos coloniais, mas também às diversas estratégias dos governos de enfraquecimento e "destruição" das indígenas como mulheres. Claudia, falando sobre a trajetória da comandanta Ramona, como exemplo para as mulheres zapatistas, acusa o "mau governo" inclusive de tentar se apropriar dos símbolos das lutas das mulheres zapatistas:

"Aunque no sabemos leer, ni escribir, ni hablar en castilla, vamos aprendiendo poco a poco; es un ejemplo que nos dejó nuestra Comandanta Ramona. Ella no sabía leer, ni escribir, ni hablar en castilla, pero fue la primera que salió a participar fuera de Chiapas. Cuando ella se fue a México, dijo "nunca más un México sin nosotras", y el mal gobierno copió lo que dijo nuestra comandanta. Cuando Vicente Fox estaba de presidente según él también lo dijo, pero él dijo "nunca más un México sin ustedes". Lo dijo para engañar a los hermanos, a los que todavía están utilizados, para llegar a gobernar en el mal gobierno" (EZLN, 2013c, p. 46).

Assim, além do histórico de opressão colonial, o descaso do estado mexicano às demandas das mulheres zapatistas soma-se também às tentativas de enfraquecimento e apropriação dos símbolos de luta para realização de um projeto de poder que não leva em consideração a participação indígena, principalmente, das mulheres indígenas. É a partir 
desses obstáculos que as zapatistas se organizam para fortalecer sua participação como mulheres dentro da luta revolucionária e frente ao Estado mexicano.

\section{Lei Revolucionária de Mulheres}

No que concerne às lutas pelos direitos das mulheres, as zapatistas destacam-se por sua capacidade de organização e autonomia. Talvez o maior dos símbolos dessa luta seja a Lei Revolucionária de Mulheres, mais importante de todas as leis revolucionárias criadas pelo EZLN ${ }^{8}$, promulgada quando o movimento ainda se encontrava na clandestinidade.

A Lei surgiu das demandas de igualdade de direitos e participação política, e da urgência de se combater problemas relacionados à condição de vida das mulheres nas comunidades indígenas de Chiapas. A partir do reconhecimento desses problemas e demandas, algumas zapatistas passaram a mobilizar outras, recorrendo todas às comunidades e juntando propostas de mulheres indígenas. Como resultando geraram o texto aprovado pela comandância geral do EZLN em março de 1993.

Desde os primeiros debates para sua criação houve descontentamento masculino nas diversas instâncias do movimento e das comunidades. Idealizada exclusivamente por mulheres incidiu questionando profundamente as relações de poder nas comunidades. Provocou indagações sobre a na hierarquia familiar e doméstica, e também sobre a estrutura, concepção e princípios do zapatismo. Buscando visibilizar e reconhecer a importância da mobilização feminina o Subcomandante Marcos declarou que a publicação dessa lei, em março de 1993, liderada pelas mulheres zapatistas representou o primeiro levante do EZLN (Carta do Subcomandante Marcos ao jornal “La Jornada”, 26/01/1994).

As demandas elaboradas pelas indígenas e contidas na Lei Revolucionária de Mulheres são estruturadas em dez princípios, sendo eles:

"Primero - Las mujeres, sin importar su raza, credo, color o filiación política, tienen derecho a participar en la lucha revolucionaria en el lugar y grado que su voluntad y capacidad determinen.

\footnotetext{
${ }^{8}$ Além da Lei Revolucionária de Mulheres, em 1993 foram promulgadas as seguintes leis revolucionárias: Lei de impostos de guerra, Lei de direitos e obrigações dos povos em luta, Lei de direitos e obrigações das Forças Armadas Revolucionárias, Lei agrária revolucionária, Lei de reforma urbana, Lei do trabalho, Lei de indústria e comércio, Lei de seguridade social e Lei de justiça.
} 
Segundo - Las mujeres tienen derecho a trabajar y recibir un salario justo.

Tercero - Las mujeres tienen derecho a decidir el número de hijos que pueden tener y cuidar.

Cuarto - Las mujeres tienen derecho a participar en los asuntos de la comunidad y tener cargo si son elegidas libre y democráticamente.

Quinto - Las mujeres y sus hijos tienen derecho a atención primaria en su salud y alimentación.

Sexto - Las mujeres tienen derecho a la educación.

Séptimo - Las mujeres tienen derecho a elegir su pareja y a no ser obligadas por la fuerza a contraer matrimonio.

Octavo - Ninguna mujer podrá ser golpeada o maltratada físicamente ni por familiares ni por extraños. Los delitos de intento de violación o violación serán castigados severamente.

Noveno - Las mujeres podrán ocupar cargos de dirección en la organización y tener grados militares en las fuerzas armadas revolucionarias.

Décimo - Las mujeres tendrán todos los derechos y obligaciones que señala las leyes y reglamentos revolucionarios"(disponível em www.palabra.ezln.org.mx).

A Lei Revolucionária de Mulheres é tratada pelas mulheres zapatistas como uma das ferramentas mais importantes para combater a desigualdade de gênero em suas comunidades (EZNL, 2003c). O primeiro dos dez artigos da Lei se intitula "participação das mulheres no governo autônomo". As zapatistas defendem que a política é o espaço onde se cria a consciência, de forma que o exercício da participação, em sua prática, é visto como o próprio caminho para a superação das desigualdades.

O argumento principal para a igualdade de participação entre mulheres e homens é de que se trata de uma luta coletiva. Comparando-se com a realidade anterior à lei, as zapatistas relatam grande avanço quanto ao direito de participar dos assuntos das comunidades, de diferentes áreas de trabalho, de se eleger livre e democraticamente, de ocupar todos os cargos de direção locais, regionais e de comandância do movimento, inclusive qualquer patente dentro do exército revolucionário. 
Dessa forma, as zapatistas ressaltam a importância de todos os membros do movimento conhecerem e estudarem esta Lei. Para tanto, são realizadas muitas reuniões para difundi-la, especialmente entre as próprias mulheres, buscando incentivar sua participação. Também é ensinada nas escolas secundárias autônomas, objetivando que os/as zapatistas se formem conhecendo as suas aplicações.

Para além da participação política, outas transformações positivas são atribuídas a Lei Revolucionária de Mulheres zapatistas. Testemunham que hoje possuem mais autonomia no planejamento familiar e que muitas famílias têm se conscientizado sobre a quantidade de filhos que podem manter. Afirmam que recentemente conquistaram a autonomia quanto à decisão de com quem se casar. Também provocou melhoras no acesso à saúde, segurança alimentar, trabalho e educação básica. A título de exemplo, vale citar um dos tantos depoimentos neste sentido:

"Antes nuestros padres no nos daban derecho a estudiar, sólo los hombres podían estudiar, pero ya no es así, ahorita tenemos que participar en diferentes trabajos y hay que aprender a leer para que así podamos ocupar los cargos. Bien sabemos que nuestra Ley Revolucionaria de las Mujeres dice que nosotras tenemos el derecho de la educación para que nosotras también aprendamos a leer y a escribir, pero no sólo eso, también es para que aprendamos, para defendernos como mujeres porque ya no queremos que sea como antes cuando estábamos muy explotadas, no teníamos la buena educación como ya tenemos ahora. Es necesario que nos eduquemos, que nos preparamos, para que así nadie ya nos va a venir a engañar ni a explotar como mujeres. Hay que prepararnos, hay que seguir adelante la educación, entonces como mujeres seguimos adelante también en la educación"(EZLN, 2003c, pp. 41-42).

Porem manifestações de violência de gênero como ameaças, tentativas, e violações são ainda latentes nas comunidades em que pese a aplicação de castigos severos. Vale lembrar que em resposta a esse fenômeno é terminantemente proibido o consumo de álcool ou qualquer tipo de drogas. Os relatos destacam também debates e mobilizações semelhantes para promover uma ampliação da Lei existente que contemple a erradicação da prostituição, o direito de defesa das mulheres agredidas verbalmente ou fisicamente, dentre outras demandas associadas as relações com esposos e familiares. Urge a tomada de consciência de pais e esposos para reconhecerem a importância da participação feminina nos espaços políticos. O ciúme e a desconfiança, traços vergonhosos do regime 
patriarcal-colonial, aparecem muitas vezes como causa do afastamento das mulheres dos cargos políticos.

A participação e organização das mulheres indígenas, apesar do impacto da Lei Revolucionária de Mulheres, não ficam restritas a ela. Paz (2012) afirma que desde a década de 1970, existiam articulações organizativas de mulheres em torno de diferentes âmbitos, como dentro da luta agrária. Deste modo, o Congresso Indígena que ocorreu em 1974 em Chiapas fomentou as ações de organizações populares, sobretudo camponesas, sendo que estas, desde o princípio, eram compostas por homens e mulheres ${ }^{9}$ (HERNÁNDEZ CASTILLO, 2001).

Para além do envolvimento com as temáticas referentes à demanda pela terra, as mulheres indígenas, que posteriormente participaram das lutas zapatistas, possuíam outro antecedente organizativo: a evangelização feminina. De acordo com Paz (2012), a ação da pastoral de religiosas através da Coordenação Diocesana de mulheres (Coordinadora Diocesana de Mujeres - CODIMUJ) em comunidades indígenas possibilitou 0 estabelecimento de espaços de encontros e de comunicação para mulheres.

\section{Desafios e formas de resistência: a participação política das mulheres zapatistas.}

"En estos tiempos que estuvimos trabajando para venir a presentarnos aquí, nos dimos cuenta que sí necesitamos trabajar más lo que es la Ley Revolucionaria de Mujeres, porque hay puntos que sí los estamos haciendo aunque sea en lo mínimo, pero hay puntos que no hemos alcanzado completarlos"(EZLN, 2003c, p. 16).

Hernández Castillo (2001: 140) afirma que a Lei Revolucionária de Mulheres, mais que uma realidade vivida, é um ideal: "la sensibilidad de género que han expresado las demandas zapatistas es sólo la semilla de una nueva cultura que aún se tiene que construir". O avanço na construção da igualdade de gênero requer ainda da luta e vigilância das mulheres. Durante a "Escuelita", as zapatistas enfatizavam tanto os avanços quanto os obstáculos à participação feminina. Dentre as dificuldades encontradas ressaltam-se as tradições, preconceitos, obrigações domésticas e profundos

\footnotetext{
${ }^{9}$ O Congresso Indígena de San Cristóbal de las Casas, ocorrido entre os dias 13 e 15 de outubro de 1974 é considerado a raiz organizativa do movimento indígena de Chiapas e do próprio EZLN. Pela primeira vez na história do México, reuniram-se mais de 500 delegados e delegadas das quatro principais etnias de Chiapas (chol, tzeltal, tzotzile tojolabal) para analisar e discutir os graves problemas que sofriam, em quatro grandes eixos: terra, educação, saúde e comércio. A teologia da libertação exerceu grande influência na organização das resistências das comunidades indígenas mexicanas, em especial em território chiapaneco.
} 
problemas sociais, como o analfabetismo, que afeta muito mais as mulheres que os homens chiapanecos.

A participação política das mulheres encontra obstáculos em todas as etapas de organização do movimento; na nomeação para os cargos, durante as atividades organizativas e na tomada de decisões políticas. Esses empecilhos desdobram-se em sentimentos de desânimo que, algumas vezes, incidem na desistência. Para Silvia, integrante da "Junta de Bom Governo" do "Caracol II - Oventik", um dos maiores problemas encontrados é o medo de não saber governar ou de não saber trabalhar (EZLN, 2003c, p. 21).

A solução para esses problemas enfrentados busca ser pensada coletivamente, o apoio coletivo torna-se a principal chave para inserção e continuação das mulheres nesses espaços políticos. De acordo com Nabil, Integrante do Conselho Autônomo, "Caracol I - La Realidad", 'são poucas as mulheres que se nomeiam voluntariamente, sendo que às vezes devem "obrigar um pouco" umas às outras para participarem" (EZLN, 2003c, p. 10).

Dito apoio entre mulheres é um trabalho realizado cotidianamente, de forma coletiva e paciente. $O$ auxílio consiste em acompanhar as atividades, mostrando a importância da participação, pois é através dela que alguns avanços podem ser observados. Neste sentido, Silvia afirma integrante da "Junta de Bom Governo", MAREZ Magdalena de la Paz, "Caracol II Oventik", que: "las compañeras se preocupan mucho por llevar bien sus cargos, pero no hay más que superarlo con la práctica, así han aprendiendo poco a poco"(EZLN, 2003c, p. 21).

No mesmo sentido, Marisol ex-integrante da "Junta de Bom Governo", MAREZ San Pedro de Michoacán, aponta exemplos práticos onde o esforço individual e o apoio coletivo contribuíram para a participação de mulheres:

"También en la Junta tenemos una compañera que no mucho, pero sí ya está avanzada, ella no sabe leer ni escribir. Estábamos todavía nosotras en el periodo de la Junta cuando a ella le tocó entrar, le ponemos atención, le mostramos lo que hacemos, le vamos enseñando lo que ella va a poder aprender, incluso empezó a escribir su nombre (EZLN, 2003c, p. 10).

Letícia ex integrante da "Junta de Bom Governo", "Caracol II - Oventik", descreve em detalhes quais os trabalhos devem ser realizados na Junta e a importância da participação e do aprendizado das práticas políticas pelas mulheres:

"El trabajo diario de la Junta incluye muchas actividades, como son registro de las actividades que se realizan, la elaboración 
de proyectos, llevan el control y manejo de recursos, aprender a usar las computadoras, aprenden cómo enviar y recibir correos, cómo hacer informes, aprender a orientar y animar a los pueblos de forma directa y también grabando mensajes para transmitir en las radios comunitarias, analizar y reflexionar los problemas y necesidades que se presentan en los pueblos. Hemos participado en algunos encuentros con otras organizaciones. Estas tareas son muy importantes para nuestros pueblos y como mujeres nos falta mucho por aprender"(EZLN, 2003c, p. 20).

Outro ponto destacado pelas mulheres é que os diferentes idiomas falados pelos pertencentes ao movimento dificultam a participação feminina nas discussões. O que tem se tentando fazer, coletivamente, é buscar maneiras para que essas mulheres compreendam as demandas colocadas e auxiliem nas tomadas de decisões. Para tal, quando alguém não compreende o idioma, o que se faz é "buscarle quién le va a traducir, porque eso es lo que a veces dicen, que no le entienden al castilla, pero se busca quién se lo traduzca"(EZLN, 2003c, p. 12).

Outro obstáculo à participação feminina é que quando viajam para alguma atividade política, muitas relatam medo de ir sozinhas, tristeza por estarem longe de suas comunidades e também intimidações e acusações de não terem documentos. Para tanto, uma das soluções encontradas foi nomear duplas de mulheres para o exercício de algumas atividades:

"También a veces tenemos el desánimo, no queremos tomar cargos porque sabemos que a lo mejor va a ser sola. Si me nombran yo sé que voy a ir en la Junta pero me siento solita porque mi pueblo no va a ir conmigo y quién sabe si allá hay compañeras. $A$ veces hay pueblos que para resolver eso lo coordinan, nombran dos compañeras en una comunidad y entonces se van las dos a hacer el trabajo. Pero no siempre las dos tienen que salir, hay veces que una de ellas se queda, pero como a esa compañerita ya la fueron encaminando porque al principio iba con la otra, ya se anima a quedar solita"(Marisol In: EZLN, 2003c, p. 11).

Os depoimentos aqui apresentados ressaltam que as zapatistas são reflexivas em relação aos inúmeros desafios que ainda devem enfrentar. Suas narrativas permitem uma aproximação ao universo de dificuldades e de respostas buscadas coletivamente pela participação das mulheres no zapatismo. 


\section{Considerações finais}

De acordo com Hernández Castillo (2001), os discursos que idealizam "o próprio" e que enfatizam os aspectos positivos de suas culturas como modo de estratégia política tornam-se perigosos quando não enfrentam os reais problemas relacionados à anti-democracia, violência e depredação que marcam internamente o cotidiano de diversos grupos indígenas. Quando se nega a existência de problemas internos, abre-se mão de enfrentá-los e buscar soluções políticas para que estes sejam resolvidos.

Neste sentido, a mobilização das mulheres zapatistas apresenta-se específico e único, não apenas por dialogarem com as teorias feministas, fazendo uso de estratégias políticas e discursivas que valorizem suas próprias formas de conhecimento, mas também e principalmente, por não negarem a existência de problemas internos e realizarem um esforço coletivo de autorreflexão. Nele se tratam as relações coloniais e, sobretudo, as relações de gênero no presente.

No movimento zapatista, as mulheres ocupam a metade dos cargos políticos nas "Juntas de Bom Governo", como autoridades em todas as áreas de trabalho nos três níveis de governo, além de possuírem organizações e cooperativas próprias. Apesar de ainda não haver igualdade na ocupação dos cargos, elas observam avanços na participação política.

A partir das trajetórias de organização política nas últimas décadas e da possibilidade de atuação conquistada pelas mulheres, a participação feminina é hoje significativa dentro do zapatismo, mobilizando uma discussão precursora no que diz respeito aos direitos das mulheres indígenas. Ainda são muitos os desafios para a efetiva igualdade entre homens e mulheres. Porém, são inspiradoras as lutas femininas e a paciência coletiva para construção de novos modelos de organização e de olhares críticos e reflexivos das mulheres indígenas de Chiapas.

\section{Referências Bibliográficas}

AGUIRRE ROJAS, Carlos Antonio. Mandar obedeciendo: las lecciones del neozapatismo mexicano. $5^{\text {a }}$ Ed. México, DF: Contrahistorias, 2010.

BARONNET, Bruno; MORA BAYO, Mariana; STAHLER-SHOLK, Richard (Coord.), Luchas "muy otras". zapatismo y autonomía en las comunidades indígenas de Chiapas. México: Universidad Autónoma Metropolitana, 2011.

BUENROSTRO Y ARELLANO, Alejandro Manuel. As raízes do fenômeno Chiapas: o já basta da resistência zapatista. São Paulo: Alfarrabio, 2002. 
CENTRO DE DERECHOS HUMANOS FRAY BARTOLOMÉ DE LAS CASAS. Entre la política sistémica y las alternativas de vida: Informe sobre la situación de los derechos humanos en Chiapas durante los gobiernos federal y estatal 2006-2012. Chiapas, 2012a.

De la Crueldad al Cinismo: Informe sobre Tortura en Chiapas. Chiapas, 2012b.

De la Tierra al asfalto: Informe de la misión civil de observación de la Red por la Paz Chiapas y Caik al Programa Ciudades Rurales Sustentables. Chiapas, 2012c.

CECEÑA, Ana Esther. Universalidad de la lucha zapatista: algunas hipótesis. Revista Chiapas, México, DF: Era, n. 2, p. 7-20, 1996a.

Los desafíos del mundo en que caben todos los mundos y la subversión Del saber histórico de la lucha. Revista Chiapas, México, DF: Era, n. 16, p. $9-30,1996 b$.

. Subjetivando el objeto de estudio, o de la subversión epistemológica como emancipación. In: CECEÑA, Ana Esther (Org.). Los desafíos de las emancipaciones en un contexto militarizado. Buenos Aires: CLACSO, jan. 2006.

DUSSEL, Enrique. 1492: El encubrimiento del Otro. Hacia el origen del "mito de la Modernidad". La Paz: Plural, 1994.

EJÉRCITO ZAPATISTA DE LIBERACIÓN NACIONAL. Declarações $e$ comunicados. Disponíveis em: <http://enlacezapatista.ezln.org.mx/> e $<$ http://palabra.ezln.org.mx/>. Acesso em: 20/01/2015.

Gobierno Autónomo I:Cuaderno de texto de primer grado del curso de "La Libertad según l@s Zapatistas". [S.l.: s.n.], 2013a. (Escuelita Zapatista).

Gobierno Autónomo II: Cuaderno de texto de primer grado del curso de "La Libertad según l@s Zapatistas". [S.l.: s.n.], 2013b. (Escuelita Zapatista).

Participación de las mujeres en el Gobierno Autónomo: Cuaderno de texto de primer grado del curso de "La Libertad según 1@s Zapatistas". [S.l.: s.n.], 2013c. (Escuelita Zapatista).

Resistencia Autónoma: Cuaderno de texto de primer grado del curso de "La Libertad según l@s Zapatistas". [S.l.: s.n.], 2013d. (Escuelita Zapatista). 
GENNARI, Emilio. CHIAPAS: As comunidades zapatistas reescrevem a história. Rio de Janeiro: Achiamé, 2002.

EZLN: passos de uma rebeldia. São Paulo: Expressão Popular, 2005.

GUERRA, Luiz Antonio B. Democracia, Justiça, Liberdade: Lições da Escuelita Zapatista. Dissertação de mestrado, Programa de Pós-Graduação em Sociologia, Universidade de Brasília, 2014.

HERNÁNDEZ CASTILLO, Aída R. Entre el etnocentrismo feminista y el esencialismo étnico. Las mujeres indígenas y sus demandas de género. Debate feminista, p. 206-229, 2001.

Aída R. "Construyendo la Utopía: esperanzas y desafíos de las mujeres chiapanecas frente al siglo XXI", en R. A. Hernández Castillo, La otra palabra. Mujeres y violencia en Chiapas, antes y después de Acteal, CIESAS/IWGIA, México, 2008, p. 140.

LANDER, Edgardo (Org.). A colonialidade do saber:eurocentrismo e ciências sociais, perspectivas latino-americanas. Buenos Aires: Clacso Livros, 2005.

LEYVA SOLANO, Xóchitl. De las Cañadas a Europa: Niveles, actores y discursos del Nuevo Movimiento Zapatista (NMZ) (1994-1997). Desacatados: Revista de Antropologia Social, México, DF, Ciesas, p. 56-88, primavera 1999.

¿Qué es el neozapatismo?. Revista Espiral:Estudios sobre Estado y Sociedade, Guadalajara,v. VI, n. 17, p. 163-201, jan/abr. 2000.

¡Chiapas es México! Autonomías indígenas: luchas políticas con una gramática moral.Íconos: Revista de FLACSO, Quito, n. 11, jul.2001.

Identidades políticas y redes de movimientos sociales en la Era de la información: El neozapatismo como estudio de caso. Revista Voces, Guatemala, ano 2, No. 1, jan/jun. 2007.

PAZ, Luz Adriana Arreola. Breves reflexiones sobre la participación política de las mujeres zapatistas. Actas del $2^{\circ}$ Congreso Interdisciplinario sobre Género y Sociedad: "Lo personal es político", 2012.

Una mirada sobre la participación política de las mujeres indígenas en el movimiento zapatista. Distintas Latitudes. Revista de Reflexión Latinoamericana. Disponível em:< http://www.distintaslatitudes.net/unamirada-sobre-participacionpoliticade-las-mujeres-indigenas-en-elmovimiento-zapatista >. Acesso em: 20/01/2015. 
QUIJANO, Aníbal. Colonialidad y modernidad/racionalidad. In: BONILLA, Heraclio (Org.). Los conquistados.1492 y la población indígena de las Américas. Quito: Libri Mundi, Tercer Mundo, 1992.

QUIJANO, Aníbal; WALLERSTEIN, Immanuel. Americanity as a concept, or the Americas in the modern world-system. International Social Sciences Journal, Malden, n. 134, 1992.

RAMÍREZ, Gloria Muñoz. EZLN: 20 y 10, el fuego y la palavra. México, DF: Rebeldía, 2003.

ROVIRA, Guiomar. "Mujeres de maíz: la voz de las indígenas de Chiapas y la rebelión zapatista. "Edit. Virus, $2^{\circ}$ edición 1999. Barcelona, España, p. 16, 1999.

SEGATO, Rita Laura. Gênero e colonialidade: em busca de chaves de leitura e de um vocabulário estratégico descolonial. e-cadernos ces, n. 18, 2012.

STREET, Susan. La palabra verdadera del zapatismo chiapaneco: Un nuevo ideario emancipatorio para la democracia. Chiapas, México, DF, Era, n. 2, p.75-94, 1996. 